\title{
The Dioxygenation Rate in Lipoxygenase Catalysis Is Determined by the Amount of Iron(III) Lipoxygenase in Solution ${ }^{\dagger}$
}

\author{
Maria J. Schilstra, Gerrit A. Veldink," and Johannes F. G. Vliegenthart \\ Bijvoet Center for Biomolecular Research, Department of Bioorganic Chemistry, Utrecht University, \\ Padualaan 8, NL-3584 CH Utrecht, The Netherlands
}

Received November 23, 1993; Revised Manuscript Received January 27, $1994^{\circ}$

\begin{abstract}
The dioxygenation rate in reactions catalyzed by lipoxygenase- 1 from soybeans has been measured as a function of the enzyme present in the $\mathrm{Fe}$ (III) form with rapid kinetic techniques. The experiments were carried out at $\mathrm{pH} 10,25^{\circ} \mathrm{C}$. The product concentration and the fraction of iron(III) lipoxygenase were monitored by measuring the absorbance at $243 \mathrm{~nm}$ and the tryptophan fluorescence at $330 \mathrm{~nm}$ (excitation at $287 \mathrm{~nm}$ ), respectively. In reactions started with $1.3 \mu \mathrm{M}$ iron(II) lipoxygenase and $9 \mu \mathrm{M}$ linoleate, the initial rate, $r_{\text {init }}$ (estimated from the increase in absorbance over the initial $0.02 \mathrm{~s}$ of the reaction), is very small $\left(4 \mathrm{~s}^{-1}\right)$. In contrast, when the reactions are started with $1.3 \mu \mathrm{M}$ iron(III) lipoxygenase, $r_{\text {init }}$ is large $\left(150 \mathrm{~s}^{-1}\right)$. In reactions started with mixtures of iron(II) and iron(III) lipoxygenase, $r_{\text {init }}$ is linearly related to the initial concentration of the $\mathrm{Fe}$ (III) enzyme form. Redistributions of the $\mathrm{Fe}(\mathrm{II})$ and $\mathrm{Fe}(\mathrm{III})$ enzyme forms during the reaction with $12 \mathrm{nM}$ enzyme and 10,50 , or $100 \mu \mathrm{M}$ linoleate appear to be directly reflected in changes in the dioxygenation rate. The observations provide solid evidence for the hypothesis that only iron(III) lipoxygenase can catalyze the hydrogen abstraction step in the dioxygenation reaction, and thus can be regarded as the active enzyme species. The observed dynamics are accurately predicted by a nonallosteric, two-step model for lipoxygenase catalysis [Schilstra et al. (1992) Biochemistry 31, 76927699].
\end{abstract}

Lipoxygenases (EC 1.13.11.12) are monomeric enzymes with a single non-heme iron cofactor. They catalyze the dioxygenation of fatty acids which contain one or more $(1 Z, 4 Z)$-pentadiene systems. The main reaction products are chiral $(E, Z)$ conjugated hydroperoxy fatty acids. In animal tissue, the dioxygenation products are the precursors of tissue hormones, such as leukotrienes and lipoxins. In plants, lipoxygenases are involved in processes such as germination and senescence, but little is known at present about their actual role in fatty acid metabolism [for reviews, see Gardner (1991), Vick and Zimmerman (1987), Kühn et al. (1986), and Schewe et al. (1986)].

The cofactor is present either as $\mathrm{Fe}$ (II) or as $\mathrm{Fe}$ (III) (De Groot et al., 1975b); there is no experimental evidence for higher oxidation states. Treatment of iron(II) lipoxygenase with an equimolar amount of the hydroperoxide product results in the oxidation of the cofactor to $\mathrm{Fe}$ (III). The oxidation of the cofactor is accompanied by the appearance of an absorbance band around 330 (De Groot et al., 1975a) and by substantial quenching of the tryptophan fluorescence of the enzyme. The fluorescence at $330 \mathrm{~nm}$ is a measure of the concentration of iron(II) lipoxygenase in the solution (see Materials and Methods).

The progress curves of the dioxygenation reaction often show a characteristic rate increase immediately after the start, generally referred to as the induction or lag period. The origin of this rate increase has been the subject of much discussion.

Kinetic models for lipoxygenase catalysis fall into two classes. In the multiple-site models, iron(II) and iron(III) lipoxygenase are both catalytically active, although not

${ }^{\dagger}$ M.J.S. is supported by a fellowship under European Community Science Programme Twinning Grant SC1-0197 to G.A.V., J.F.G.V., A. Finazzi-Agrò, and L. Avigliano.

* To whom correspondence should be addressed.

- Abstract published in Advance ACS Abstracts, March 1, 1994. necessarily to the same extent (Smith \& Lands, 1972; Egmond et al., 1976, 1977; Lagocki et al., 1976; Schewe et al., 1986; Wang et al., 1993). The fatty acid substrate and product, $S$ and $P$, bind not only to a catalytic site but also to one or more regulatory binding sites. All multiple-site models have been invoked specifically to explain the occurrence of the initial rate increase.

In the two-step model (De Groot et al., 1975b; Ludwig et al., 1987; Schilstra et al., 1992), only iron(III) lipoxygenase can catalyze the first step of the reaction, namely, hydrogen abstraction from $S$ to form the radical $S^{o x}$. In the second reaction step, insertion of $\mathrm{O}_{2}$ at $\mathrm{C}-1$ or $\mathrm{C}-5$ of the pentadiene system leads to the formation of $\mathrm{P}$. Hydrogen abstraction is coupled to reduction of the iron cofactor to $\mathrm{Fe}(\mathrm{II})$, and $\mathrm{O}_{2}$ insertion is accompanied by its reoxidation to $\mathrm{Fe}$ (III). S and $P$ compete for a single binding site on both iron(II) and iron(III) lipoxygenase. The two-step mechanism thus attaches a central role to the cycling between the $\mathrm{Fe}$ (II) and $\mathrm{Fe}$ (III) enzyme forms. In two previous publications (Schilstra et al., 1992, 1993), we have shown that this two-step mechanism also predicts the occurrence of an induction period. Owing to occasional dissociation of the lipoxygenase-S ${ }^{0 x}$ complex, a small fraction of inactive iron(II) lipoxygenase is constantly being formed during the reaction. The Fe(III) enzyme form is regenerated by the reaction product $P$ (De Groot et al., $1975 \mathrm{~b}$ ). The system tends toward a steady-state, in which the rate of regeneration equals the rate at which iron(III) lipoxygenase disappears. The higher $[P]$, the higher the regeneration rate, and the larger the steady-state fraction of the active $\mathrm{Fe}$ (III) enzyme form. At high enzyme concentrations $(>20 \mathrm{nM})$, steady-state is reached relatively late in the reaction. As a result, the progress curves of reactions initiated with iron(II) lipoxygenase are very different from those initiated with the $\mathrm{Fe}$ (III) enzyme form. With decreasing enzyme concentration, the pre-steady-state differences between these reactions become less pronounced. At lipoxygenase 
concentrations of $1 \mathrm{nM}$ and lower, the curves coincide within the experimental error, as observed by De Groot et al. (1975a). Reactions initiated with low concentrations of either iron(II) or iron(III) lipoxygenase have "induction periods" whose duration is inversely proportional to the enzyme concentration. It should be noted that, at these low enzyme concentrations, the rate increase occurs after the system has reached the steadystate (i.e., has approached the steady-state within experimental error; Schilstra et al., 1993). The use of terms such as "induction period" or "lage phase" to describe the early stages of reactions initiated with low concentrations of lipoxygenase may give rise to confusion, since these terms usually imply non-steady-state situations.

Recently, Wang et al. (1993) reported that the time course of a reaction initiated with a very high concentration $(0.43$ $\mu \mathrm{M}$ ) of iron(III) lipoxygenase was very similar to that of a reaction initiated with the same amount of iron(II) lipoxygenase. Neither of the product formation curves showed an induction period. However, in a reaction initiated with $2 \mu \mathrm{M}$ iron(II) lipoxygenase, the quenching of tryptophan fluorescence (see above) showed a clear lag period. On the basis of these results, the authors rejected all models in which iron(III) lipoxygenase is the only catalytically active species, in favor of a multiple-site mechanism.

In this paper, we report a detailed investigation into the relationship between the dioxygenation rate and the ratio of iron(II) to iron(III) lipoxygenase. In all experiments, the protein fluorescence $(330 \mathrm{~nm})$ as well as the product absorbance $(243 \mathrm{~nm})$ was measured. One set of experiments was performed at a very high lipoxygenase concentration $(1.3 \mu \mathrm{M})$, similar to the concentrations used by Wang et al. (see above). The second set was performed at a much lower concentration of lipoxygenase (12 nM). We compare the experimental results with predictions for the pre-steady-state redistribution of enzyme species during the reaction, based upon the twostep model. Furthermore, we discuss the merits of the two models in light of the results reported here and in previous publications.

\section{MATERIALS AND METHODS}

Materials. The purification of lipoxygenase from soybeans (White Hilum) and the preparation of (13S)-HPOD ${ }^{1}[(13 S)$ hydroperoxy- $(9 Z, 11 E)$-octadecadienoic acid] have been described previously (Finazzi-Agrò et al., 1973; Schilstra et al., 1992). The concentration of lipoxygenase was calculated from the absorbance at $280 \mathrm{~nm}(1.6 \mathrm{AU}$ at $1 \mathrm{mg} / \mathrm{mL}$ lipoxygenase $)$. The specific activity of the lipoxygenase preparation was 150 $\mu \mathrm{mol} \cdot \mathrm{min}^{-1} \cdot \mathrm{mg}^{-1}$. It was stored at a concentration of $17 \mathrm{mg} /$ $\mathrm{mL}$, at $4{ }^{\circ} \mathrm{C}$ in $0.05 \mathrm{M}$ sodium acetate buffer, $\mathrm{pH} 5.5$, containing $134 \mathrm{~g} / \mathrm{L}$ ammonium sulfate. Iron(III) lipoxygenase was prepared by preincubating iron(II) lipoxygenase with a 2-fold molar excess of 13-HPOD for approximately $3 \mathrm{~min}$, and was used immediately after its preparation. Linoleic acid $[(9 Z, 12 Z)$-octadecadienoic acid] was purchased from Sigma. Solutions of linoleic acid ( $300 \mathrm{mM})$ and 13-HPOD $(200 \mathrm{mM})$ were stored under argon in methanol p.a. (Merck).

Fluorescence Spectra. Fluorescence spectra were recorded on a Perkin-Elmer fluorescence spectrophotometer MPF-2A in a $10-\mathrm{mm}$ cuvette. Slit widths of $8-\mathrm{nm}$ width were used for both excitation and emission.

Kinetic Measurements. All reactions were performed at $25^{\circ} \mathrm{C}$ in a $0.1 \mathrm{M}$ sodium borate buffer, $\mathrm{pH} 10$ (BB10). At $\mathrm{pH} 10$, the critical micelle concentration of linoleate is

${ }^{1}$ Abbreviations: HPOD, hydroperoxyoctadecadienoic acid; BB10, 0.1 $\mathrm{M}$ sodium borate buffer, $\mathrm{pH}$ 10; EPR, electron paramagnetic resonance. approximately $200 \mu \mathrm{M}$ (Verhagen et al., 1978b), and lipoxygenase-1 from soybeans has maximum activity. Reactions were carried out at final lipoxygenase concentrations of 1.3 $\mu \mathrm{M}$ or $12.5 \mathrm{nM}$; the final linoleate concentrations were 10 , 50 , or $100 \mu \mathrm{M}$. The methanol concentration was $0.03 \%(v / v)$ in all measurements. The increase of the HPOD concentration was followed in a Hi-Tech Scientific SF-51 stopped-flow apparatus, equipped with an LS-10 light source and a PM-60 photomultiplier. The monochromator was set at $243 \mathrm{~nm}$, and a UG-5 filter (transmission band $230-400 \mathrm{~nm}, 45 \%$ transmission at $243 \mathrm{~nm}$ ) was used to prevent stray light of wavelengths longer than $400 \mathrm{~nm}$ from entering the photomultiplier. The extinction coefficient of HPOD at $243 \mathrm{~nm}$ is $17.8 \times 10^{3} \mathrm{~L} \cdot \mathrm{mol}^{-1} \cdot \mathrm{cm}^{-1}$.

Tryptophan fluorescence (excitation at $287 \mathrm{~nm}$, emission at $330 \mathrm{~nm}$ ) is a good measure of the concentration of iron(II) lipoxygenase in solution, as the following arguments show. Iron(II) lipoxygenase is EPR-silent, but iron(III) lipoxygenase shows a band in the EPR spectrum at $g=6$ (De Groot et al., 1975b). The intensity of the EPR signal at $g=6$, and therefore the amount of iron(III) lipoxygenase in the solution, is linearly related to the intensity of a band at $330-400 \mathrm{~nm}$ in the UV absorbtion spectrum of lipoxygenase (Slappendel et al., 1983). The EPR signal and the absorbance band stay unchanged after extensive dialysis of the lipoxygenase solution (Van der Heijdt, 1992). Therefore, these signals are related to the valence state of the iron cofactor, and not, for example, to the binding of the fatty acid product. The appearance of the absorbance band around $370 \mathrm{~nm}$ is accompanied by significant quenching of the tryptophan fluorescence. The quenching is attributed to nonradiative energy transfer between the tryptophans and the chromophore responsible for the 370-nm absorbance band (Egmond et al., 1975). When iron(II) lipoxygenase is titrated with 13-HPOD, the EPR signal at $g$ $=6$ and the absorbance at $370 \mathrm{~nm}$ both increase linearly, and the tryptophan fluorescence decreases linearly, until the ratio of HPOD to lipoxygenase is 1 (Slappendel et al., 1983; this paper, Figure 1c). Therefore, the tryptophan fluorescence is linearly related to the amount of iron(II) lipoxygenase in the solution.

The changes in tryptophan fluorescence were measured in a Hi-Tech Scientific SF-61 stopped-flow apparatus, equipped with an LS-175 light source. The excitation wavelength was $287 \mathrm{~nm}$. A WG-320 filter was positioned before the photomultiplier to cut off light of wavelengths shorter than $300 \mathrm{~nm}$. The time constant was $33 \mu$ s for measurements at $1.3 \mu \mathrm{M}$ lipoxygenase and $330 \mu \mathrm{s}$ for measurements at $12.5 \mathrm{nM}$. The reactions were recorded for $0.2-0.5 \mathrm{~s}(1.3 \mu \mathrm{M}$ lipoxygenase) and $10 \mathrm{~s}$ (12.5 $\mathrm{nM}$ lipoxygenase) at 512 points per trace. Approximately 10 traces were averaged to produce a final curve. Initial rates in the reactions with $1.3 \mu \mathrm{M}$ lipoxygenase were estimated from the amont of HPOD formed during the first $0.02 \mathrm{~s}$ of the reaction. For estimation of the dioxygenation rates during the reaction, high-frequency noise was removed from the absorbance curves using a 25-point Fourier transform filter. Product formation rates during the reaction, $r_{i}$, at time $t_{\text {i }}$ were calculated from the smoothed curves using $r_{i}=$ $\left([\mathrm{HPOD}]_{i}-[\mathrm{HPOD}]_{i-1}\right) /\left(t_{i}-t_{i-1}\right)$.

Numerical Simulations. Numerical simulations of the lipoxygenase reaction were performed on a Hewlett Packard Vectra ES/12 (AT), equipped with a mathematical coprocessor. The simulations were based on the mechanism in Scheme 1. The rate equations given in Schilstra et al. (1992) (eq 1-15) were used, with one modification: we now describe the oxygen insertion step as a simple bimolecular reaction between the substrate radical in the active site and $\mathrm{O}_{2}$. 
Scheme $I^{a}$

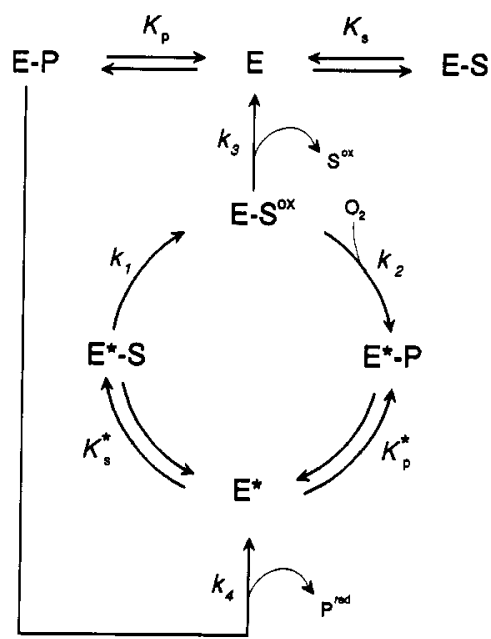

a Abbreviations: $\mathrm{E}$ and $\mathrm{E}^{*}$, iron(II) and iron(III) lipoxygenase, respectively; $S$, polyunsaturated fatty acid substrate; $P$, hydroperoxy fatty acid product; $S^{\circ x}$ and Pred, oxidized and reduced forms of $S$ and $P$ (radical compounds); $K_{\mathrm{s}}, K_{\mathrm{p}}, K^{*}$ s, and $K^{*}$ p, equilibrium dissociation constants of $\mathrm{E}-\mathrm{S}, \mathrm{E}-\mathrm{P}, \mathrm{E}^{*}-\mathrm{S}$, and $\mathrm{E}^{*}-\mathrm{P}$, respectively; $k_{1}, k_{3}$, and $k_{4}$, monomolecular rate constants; $k_{2}$, bimolecular rate constant.

Therefore, we used $f_{31}=k_{2}\left[\mathrm{O}_{2}\right]$, instead of eq 14 from Schilstra et al. (1992). The reason for this is that the hydrogen abstraction step is rate-limiting at $\left[\mathrm{O}_{2}\right]=240 \mu \mathrm{M}$ (Egmond et al., 1973). The value of $f_{31}$, the oxygen insertion rate, must therefore be much larger than $k_{1}$ (i.e., $f_{31}$ is about $10^{5}$ ). For that reason, the bimolecular rate constant $k_{2}$ is likely to be close to the diffusion-controlled limit of $10^{9} \mathrm{M}^{-1} \cdot \mathrm{s}^{-1}$.

The values of the parameters used in the simulations are based on values estimated by Aoshima et al. (1977) $\left(K_{\mathrm{p}}=16\right.$ $\left.\mu \mathrm{M}, k_{4}=250 \mathrm{~s}^{-1}\right)$, Egmond et al. (1973) $\left(K_{\mathrm{s}}^{*}=23 \mu \mathrm{M}, k_{1}\right.$ $\left.=200 \mathrm{~s}^{-1}\right)$, Egmond et al. (1976) $\left(K_{\mathrm{s}}^{*}=20 \mu \mathrm{M}, k_{1}=320\right.$ $\left.\mathrm{s}^{-1}\right)$, Schilstra et al. (1992) $\left(K_{\mathrm{s}}^{*}=15 \mu \mathrm{M}, K^{*}{ }_{\mathrm{p}}=24 \mu \mathrm{M}, k_{1}\right.$ $\left.=350 \mathrm{~s}^{-1}\right)$, Schilstra et al. (1993) $\left(K_{\mathrm{s}} \approx 20 \mu \mathrm{M}, k_{2}\left[\mathrm{O}_{2}\right] / k_{3}\right.$ $\approx 100)$, Verhagen et al. (1978a) $\left(k_{1} / k_{4}=2\right)$, and Wang et al. (1993) $\left(K^{*}{ }_{\mathrm{s}}=12 \mu \mathrm{M}, K_{\mathrm{p}}^{*}=50 \mu \mathrm{M}\right)$. In the simulations, $K^{*}, K^{*}{ }_{\mathrm{p}}, K_{\mathrm{p}}$, and $K_{\mathrm{s}}$ were all set at a value of $20 \mu \mathrm{M}$ (increasing $K^{*}{ }_{\mathrm{p}}$ to values up to $60 \mu \mathrm{M}$ did not significantly affect the outcome of the simulations). For the other parameters, we used the following values: $k_{1}=300 \mathrm{~s}^{-1}, k_{4}=150 \mathrm{~s}^{-1}, k_{2}=$ $1 \times 10^{9} \mathrm{M}^{-1} \cdot \mathrm{s}^{-1}$, and $k_{3}=2.3 \times 10^{3} \mathrm{~s}^{-1}$. In all simulations, the starting concentration of $\mathrm{O}_{2}$ was $240 \mu \mathrm{M}$.

\section{RESULTS}

Fluorescence Spectra of Iron(II) and Iron(III) Lipoxygenase. The fluorescence excitation and emission spectra of $1.5 \mathrm{nM}$ native [i.e., iron(II)] lipoxygenase in $3 \mathrm{~mL}$ of $\mathrm{BB} 10$ were recorded. Excitation and emission maxima were found at 287 and $328 \mathrm{~nm}$, in accordance with earlier observations (Egmond et al., 1975). When the enzyme was converted into its $\mathrm{Fe}$ (III) form (by adding $3 \mathrm{nmol}$ of 13-HPOD in $10 \mu \mathrm{L}$ of BB10), 25\% quenching of the fluorescence intensity at 330 $\mathrm{nm}$ (excitation at $287 \mathrm{~nm}$ ) was observed. The positions of the excitation and emission maxima were unchanged. When a further $15 \mathrm{nmol}$ of 13-HPOD was added, the fluorescence spectra did not change significantly. The experimental error on the peak intensity was approximately $5 \%$.

Relationship between the Initial Rate and Initial Distribution of $\mathrm{Fe}(I I)$ and $\mathrm{Fe}(I I I)$ Enzyme Forms at $1.3 \mu \mathrm{M}$ Lipoxygenase. In order to investigate the relationship between the initial fraction of iron(III) lipoxygenase and the dioxygenation rate immediately after the start of the reaction, we used stopped-flow techniques to study the dioxygenation of
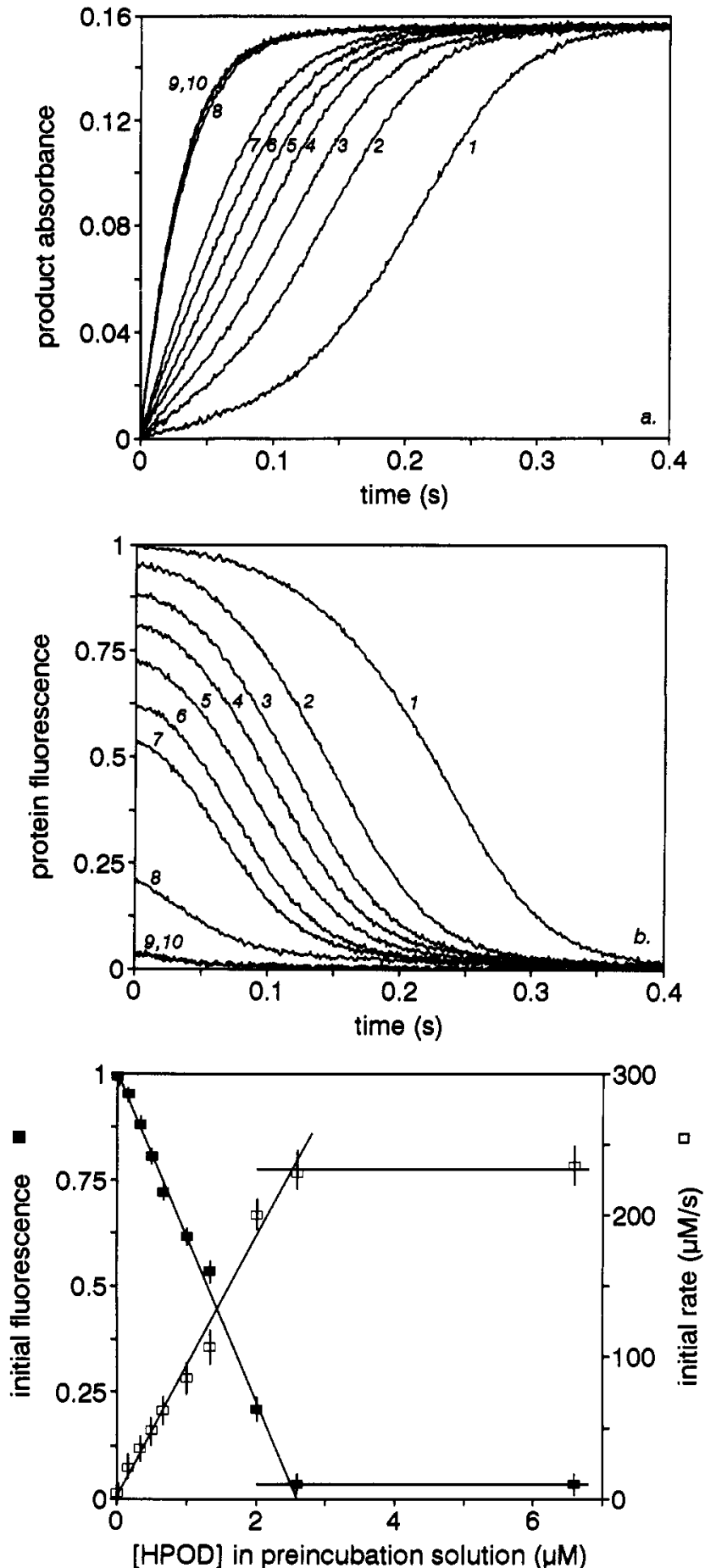

FIGURE 1: Dependence of the time course of the linoleate dioxygenation reaction on the fraction of enzyme present in $\mathrm{Fe}$ (III) form at the beginning of the reaction. Iron(II) lipoxygenase $(2.5 \mu \mathrm{M})$ was preincubated with increasing amounts of $(13 S)$-HPOD (curves 1 , no HPOD added; $2,0.16 \mu \mathrm{M} ; 3,0.34 \mu \mathrm{M} ; 4,0.50 \mu \mathrm{M} ; 5,0.68 \mu \mathrm{M} ; 6$, $0.1 .0 \mu \mathrm{M} ; 7,1.4 \mu \mathrm{M} ; 8,2.0 \mu \mathrm{m} ; 9,2.6 \mu \mathrm{M} ; 10,6.6 \mu \mathrm{M}$ HPOD). Concentrations after stopped-flow mixing: lipoxygenase (total), 1.3 $\mu \mathrm{M}$ (approximately); linoleate, $9 \mu \mathrm{M}$. Panel a: absorbance at 243 nm (monitors hydroperoxide product), Panel b: tryptophan fluorescence [excitation at $287 \mathrm{~nm}$, emission above $320 \mathrm{~nm}$, monitors fraction of iron(II) lipoxygenase]; a decrease from 1 to 0 on the indicated scale corresponds to a decrease in fluorescence of approximately 25\%. Panel c: comparison of the fluorescence at $t=0$ (same scale as in panel b) with the initial rate, estimated from the curves in panel a.

$9 \mu \mathrm{M}$ linoleate catalyzed by $1.3 \mu \mathrm{M}$ lipoxygenase. Since the rate of product formation is proportional to the enzyme concentration, absolute differences between initial product formation rates will be larger at high than at low enzyme concentrations. Iron(II) lipoxygenase (approximately $2.5 \mu \mathrm{M}$ 

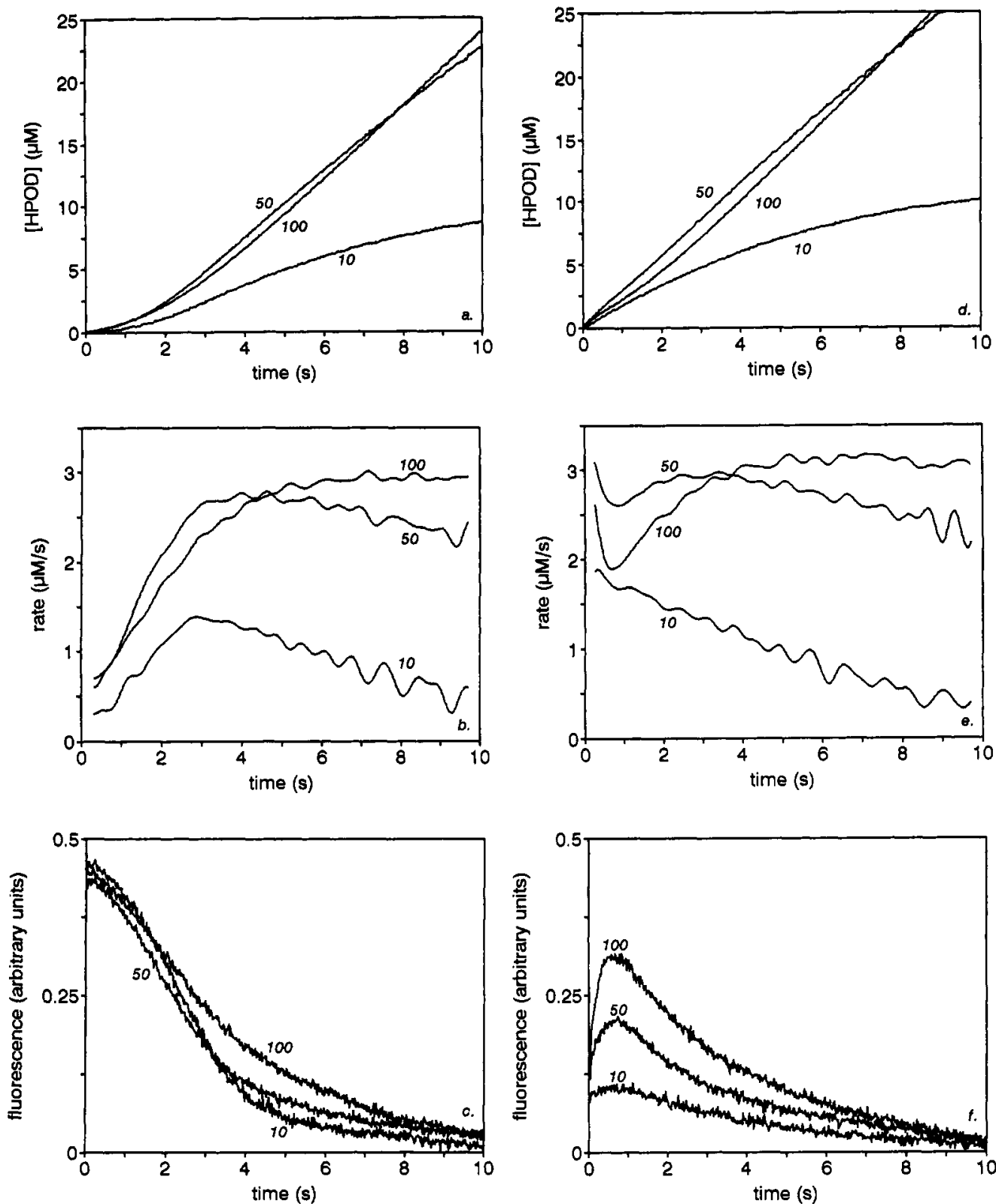

FIGURE 2: Comparison of changes in the dioxygenation rate with changes in the fraction of iron(II) lipoxygenase during the initial stages of the reaction. Panels a-c: reactions initiated with $12 \mathrm{nM}$ iron(II) lipoxygenase. Panels $\mathrm{d}-\mathrm{f}$ : reactions initiated with $12 \mathrm{nM}$ iron(III) lipoxygenase. Curves 10,50 and 100: dioxygenation of 10,50 , or $100 \mu \mathrm{M}$ linoleate, respectively. Panels a and d, increase of hydroperoxide product concentration; panels $b$ and $e$, dioxygenation rates calculated from the curves in panels a and $d$ (first derivatives); panels $c$ and $f$, changes in tryptophan fluorescence.

before stopped-flow mixing) was preincubated for approximately 3 min with different concentrations of 13-HPOD (0-8 $\mu \mathrm{M})$. The increase in product concentration was monitored by measuring the absorbance at $243 \mathrm{~nm}$. In a separate experiment, under exactly the same conditions, the change of the fluorescence at $330 \mathrm{~nm}$ (excitation at $287 \mathrm{~nm}$ ) was recorded in order to monitor the conversion of iron(II) into iron(III) lipoxygenase.

The results are shown in Figure 1. In contrast to Wang et al. (1993), we find a large difference between the reactions initiated with iron(II) lipoxygenase (curves 1 , panels a and b) and iron(III) lipoxygenase (curves 9 and 10, panels a and b). The reaction initiated with iron(II) lipoxygenase shows a relatively long lag phase, both in the absorbance and in the fluorescence curves. In the reaction started with iron(III) lipoxygenase, 13-HPOD is produced at a very high rate at the beginning of the reaction. These curves do not show a lag phase.

When $2.5 \mu \mathrm{M}$ iron(II) lipoxygenase is preincubated with $0.16-6.6 \mu \mathrm{M} 13-\mathrm{HPOD}$, the duration of the lag phase decreases as [13-HPOD] increases (Figure 1, curves 2-8). After preincubation with 13-HPOD concentrations greater than 0.35 $\mu \mathrm{M}$, the lag phase is no longer apparent in the absorbance curves (curves 5-8, Figure 1a). The fluorescence curves, however, remain sigmoidal up to 13-HPOD concentrations of approximately $1.5 \mu \mathrm{M}$ (curves $2-7$, Figure 1b). In Figure 1c, the initial rates, estimated from the absorbance plots, and the initial fluorescence intensity are plotted as a function of the concentration of 13-HPOD in the preincubation solution. The initial fluorescence decreases linearly with increasing concentrations of 13-HPOD, whereas the initial rates increase linearly. Maximum initial rate and minimum initial fluorescence are reached at approximately $2.5 \mu \mathrm{M}$ 13-HPOD. The initial deoxygenation rate is, therefore, linearly related to the fraction of iron(III) lipoxygenase at the start of the reaction. The initial rate is almost zero when the reaction is initiated with untreated $\mathrm{Fe}$ (II) enzyme. Since the linoleate preparation that was used in the experiments contains some $0.2 \% 13 S$-HPOD (Schilstra et al., 1993), a small, but finite, 

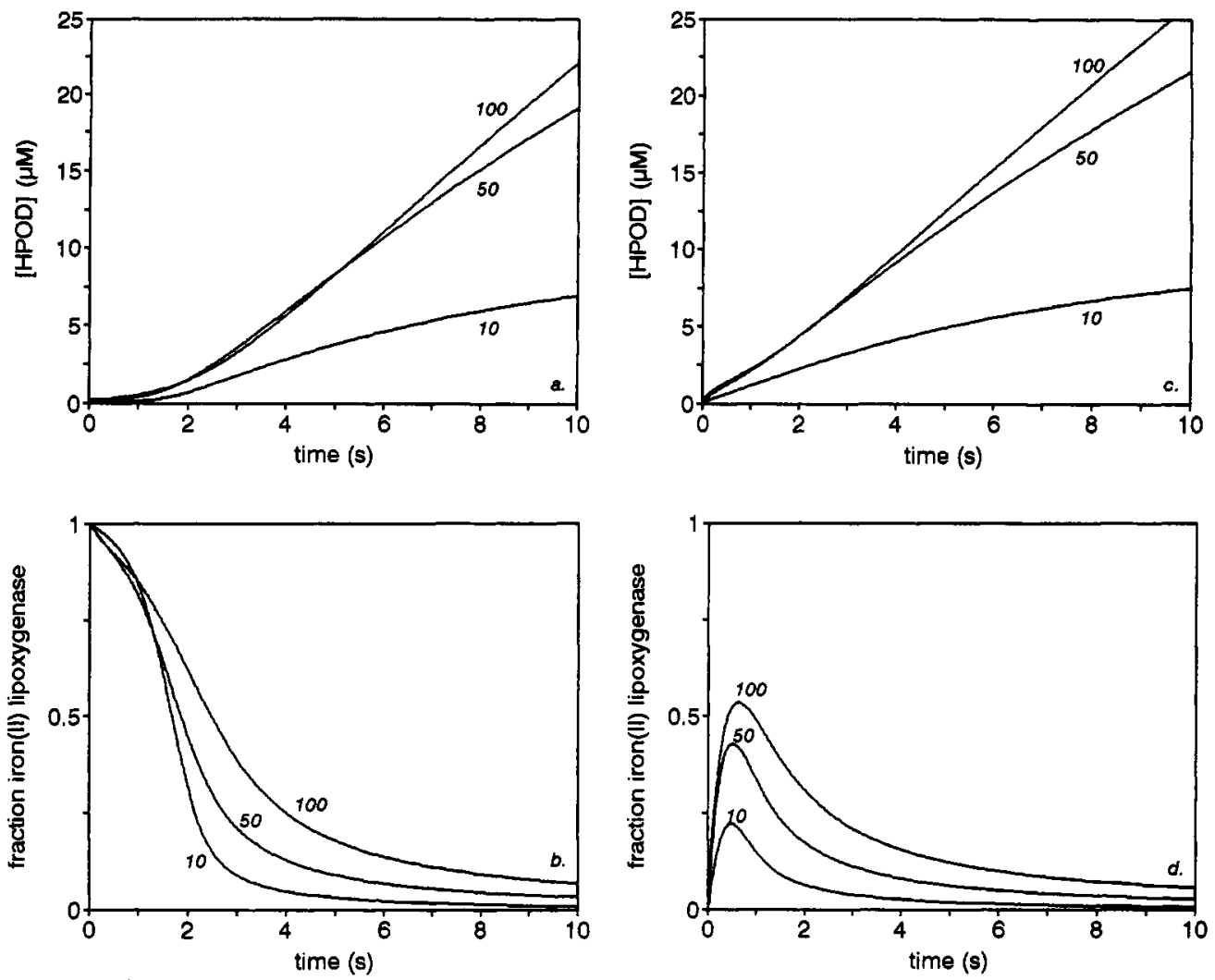

FIGURE 3: Numerical simulation of initial stages in the dioxygenation of 10,50 , or $100 \mu \mathrm{M}$ linoleate (curves $10,50,100$ ). The simulations were started with $12 \mathrm{nM}$ iron(II) lipoxygenase (panels a, b) or $12 \mathrm{nM}$ iron(III) lipoxygenase (panels c, d). The simulations were based upon the nonallosteric two-step model in Scheme 1 (see Materials and Methods for parameter values). Panels a, c, increase of hydroperoxide product concentration; panels $b$, $d$; changes in the fraction of iron(II) lipoxygenase.

initial rate in the reaction started with iron(II) lipoxygenase is expected.

Redistribution of Iron(II) and Iron(III) Lipoxygenase during the Dioxygenation Reaction at $12 \mathrm{nM}$ Lipoxygenase. The differences between reactions initiated with iron(II) and iron(III) lipoxygenase become smaller when the enzyme concentration is lower (Schilstra et al., 1993). Progress curves of reactions started with $12 \mathrm{nM}$ iron(III) lipoxygenase show a clear lag period after an initial burst (Schilstra et al., 1992). To study the redistribution of enzyme species during reactions initiated with $12 \mathrm{nM}$ iron(II) and iron(III) lipoxygenase, the tryptophan fluorescence was recorded during the first $10 \mathrm{~s}$ in the dioxygenation of 10,50 , and $100 \mu \mathrm{M}$ linoleate. In Figure 2 , we show the product formation curves (a and d), their first derivatives (i.e., the rates of product formation; $b$ and $e$ ), and the changes in fluorescence during the reaction ( $c$ and $f$ ). In reactions initiated with iron(II) lipoxygenase $(a-c)$, the reaction rate increases for some 3-6 s and then reaches a maximum, whereas the fluorescence decreases sigmoidally. For all three concentrations of linoleate, the maximum rate is reached before the fluorescence change is complete. The dioxygenation of 50 and of $100 \mu \mathrm{M}$ linoleate (d), started with $12 \mathrm{nM}$ iron(III) lipoxygenase, shows a clear decrease in rate for approximately $1 \mathrm{~s}$, followed by an increase (e). The burst is associated with a pronounced increase in fluorescence ( $f$ ). In the reaction with $10 \mu \mathrm{M}$ linoleate, the fluorescence still shows a small maximum at $1 \mathrm{~s}$, but there is not clear minimum in the curve of the rate. In all three cases, the rate reaches a maximum before the fluorescence change is complete, as in the reactions initiated with iron(II) lipoxygenase.

These experiments clearly show that changes in the dioxygenation rate during the reaction coincide with changes in the distribution of iron(II) and iron(III) lipoxygenase species, as predicted by the two-step model [see Figure 6 in Schilstra et al. (1993)].
Comparison of Observed and Predicted Data. We carried out numerical integrations (non-steady-state) on the basis of the two-step model at very high $(1.3 \mu \mathrm{M})$ and at low $(12 \mathrm{nM})$ enzyme concentrations. The calculations simulate the experimental relationship between the initial fraction of iron(III) lipoxygenase, $f\left(e^{*}\right)_{\text {init }}$, and the initial rate very well. They also predict that the curve for the redistribution of iron(II) and iron(III) lipoxygenase during the reaction is sigmoidal from $f\left(e^{*}\right)_{\text {init }}=0$ up to $f\left(e^{*}\right)_{\text {init }}=0.8$, while the product formation curve only shows a clear induction period when $f\left(e^{*}\right)_{\text {init }}<0.4$ (now shown).

In Figure 3, the results of the simulations for $12 \mathrm{nM}$ lipoxygenase are shown. Comparison of Figure 3a,d with Figure 2a,b, respectively, demonstrates that the two-step model is clearly able to predict the observed shapes of the reaction progress curves over a large range of linoleate concentrations. In the two-step model, redistributions of iron(II) and iron(III) lipoxygenase are directly coupled to changes in the dioxygenation rate. The predicted redistributions during the first $10 \mathrm{~s}$ of the reactions started with iron(II) or iron(III) lipoxygenase are indicated in Figure $3 \mathrm{~b}, \mathrm{~d}$. In the simulations, the rate also reaches a maximum before the fraction of iron(II) lipoxygenase has decreased fully. This is due to changes in the substrate and product concentrations. Comparison of Figure $3 b, d$ with Figure $2 c$,f illustrates that the predicted redistributions are very similar to the observed interconversions of iron(II) and iron(III) lipoxygenase (Figure 2c,f).

\section{DISCUSSION}

The results presented in this paper provide strong evidence for the hypothesis that iron(III) lipoxygenase is the only catalytically active species. First, the dioxygenation rate immediately after the start of the reaction appears to be linearly related to the initial fraction of iron(III) lipoxygenase in the 
enzyme preparation. It is close to zero when the enzyme present at the beginning of the reaction is fully reduced. Second, changes in the distribution of the $\mathrm{Fe}$ (II) and $\mathrm{Fe}$ (III) enzyme species during the reaction are coupled to changes in the dioxygenation rate. Finally, numerical integrations based on the two-step model accurately predict the observed redistribution of enzyme species during the reaction.

The initial rate in reactions initiated with $1.3 \mu \mathrm{M}$ iron(II) lipoxygenase is very different from that in a reaction started with $1.3 \mu \mathrm{M}$ iron(III) lipoxygenase. Therefore, our observations at high enzyme concentration contradict those of Wang et al. (1993). We were unable to reproduce the reported coincidence of the reactions initiated with very high enzyme concentrations. However, the fluorescence and absorbance traces shown in Figure 1 of Wang et al. are remarkably similar to traces 5-7 in our Figure 1a,b. These traces (5-7) were obtained with $25-40 \%$ oxidized lipoxygenase. Therefore, Wang et al. may have used lipoxygenase that was partially oxidized before the start of the reaction.

The observations presented in this paper exclude models in which iron(II) and iron(III) lipoxygenases have similar catalytic activity [e.g., see the models proposed by Egmond et al. $(1976,1977)$ and Wang et al. (1993)]. The results do not exclude the possibility that there are multiple binding sites for fatty acid on lipoxygenase [cf. the mechanism that is proposed in Schewe et al. (1986)].

Viable models for lipoxygenase catalysis should at least include iron(III) lipoxygenase as the active species and predict the occurrence of an induction period, product inhibition and stimulation, substrate inhibition, and radical reactions without the participation of $\mathrm{O}_{2}$. Multiple-site mechanisms that include these well-documented experimental observations will require definition of at least eight, but probably more, parameters. The rate equations based upon such multiple-site mechanisms will have quadratic or cubic terms, and some of the coefficients in the steady-state rate equations will be the product of several "microscopic" equilibrium constants [cf. the equations in Egmond et al. (1976) or in Wang et al. (1993)]. Without doubt, such equations will accurately fit data obtained during the period in the beginning of the reaction in which the rate increases (the "steady-state lag period", but see the introduction).

However, it is not necessary to invoke multiple fatty acid binding sites on lipoxygenase to explain the occurrence of an induction period, product stimulation, or substrate inhibition. As we have shown, these phenomena are intrinsic to the simple two-step mechanism, in which $\mathrm{S}$ and $\mathrm{P}$ bind to a single binding site on both iron(II) and iron(III) lipoxygenase. The basic mechanism needs the definition of seven parameters (see Materials and Methods). The values of five of these parameters have been determined independently by a number of authors. In a previous study (Schilstra et al., 1993), we estimated the values of the other two parameters. Simulations of the dioxygenation reaction, based upon the simple two-step mechanism and using these values, predict all the observations without requiring the definition of further parameters.

In conclusion, in light of the strong experimental support for the hypothesis that iron(III) lipoxygenase is the catalytically active species in the dioxygenation of polyunsaturated fatty acids, the nonallosteric two-step model for lipoxygenase catalysis offers the simplest and most plausible explanation for all the observed phenomena.

\section{ACKNOWLEDGMENT}

We thank Dr. David R. Trentham and the staff members of the Division of Physical Biochemistry at the National Institute for Medical Research (London) for allowing us to use their stopped-flow apparatus. We are indebted to Dr. Stephen R. Martin (National Institute for Medical Research) for helpful discussions and for critically reading the manuscript. The computer program KSIM for numerical simulation (Gear method) was kindly provided by Dr. Neil C. Millar (King's College, London).

\section{REFERENCES}

Aoshima, H., Kajiwara, T., Hanataka, A., Nakatani, H., \& Hiromi, K. (1977) Biochim. Biophys. Acta 486, 121-126.

De Groot, J. J. M. C., Garssen, G. J., Veldink, G. A., Vliegenthart, J. F. G., Boldingh, J., \& Egmond, M. R. (1975a) FEBS Lett. $56,50-54$.

De Groot, J. J. M. C., Veldink, G. A., Vliegenthart, J. F. G., Boldingh, J., Wever, R., \& Van Gelder, B. F. (1975b) Biochim. Biophys. Acta 377, 71-79.

Egmond, M. R., Veldink, G. A., Vliegenthart, J. F. G., \& Boldingh, J. (1973) Biochem. Biophys. Res. Commun. 54, 1178-1184.

Egmond, M. R., Finazzi-Agrò, A., Fasella, P. M., Veldink, G. A., \& Vliegenthart, J. F. G. (1975) Biochim. Biophys. Acta 397, 43-49.

Egmond, M. R., Brunori, M., \& Fasella, P. M. (1976) Eur. J. Biochem. 61, 93-100.

Egmond, M. R., Fasella, P. M., Veldink, G. A., Vliegenthart, J. F. G., \& Boldingh, J. (1977) Eur. J. Biochem. 76, 469-479.

Finazzi-Agrò, A., Avigliano, L., Veldink, G. A., Vliegenthart, J. F. G., \& Boldingh, J. (1973) Biochim. Biophys. Acta 326, $462-470$.

Gardner, H. W. (1991) Biochim. Biophys. Acta 1084, 221-239.

Kühn, H., Schewe, T., \& Rapoport, S. M. (1986) Adv. Enzymol. Relat. Areas Mol. Biol. 58, 273-311.

Ludwig, P., Holzhütter, H.-G., Colosimo, A., Silvestrini, M. C., Schewe, T., \& Rapoport, S. M. (1987) Eur.J. Biochem. 168, 325-337.

Parker, C. W. (1987) Annu. Rev. Immunol. 5, 65-84.

Schewe, T., Rapoport, S. M., \& Kühn, H. (1986) Adv. Enzymol. Relat. Areas Mol. Biol. 58, 191-273.

Schilstra, M. J., Veldink, G. A., Verhagen, J., \& Vliegenthart, J. F. G. (1992) Biochemistry 31, 7692-7699.

Schilstra, M. J., Veldink, G. A., \& Vliegenthart, J. F. G. (1993) Biochemistry 32, 7686-7691.

Slappendel, S., Veldink, G. A., Vliegenthart, J. F. G., Aasa, R., \& Malmström, B. G. (1983) Biochim. Biophys. Acta 747, 32-36.

Smith, W. L., \& Lands, W. E. M. (1972) J. Biol. Chem. 247, 1038-1047.

Van der Heijdt, L. M., Feiters, M. C., Navaratnam, S., Nolting, H.-F., Hermes, C., Veldink, G. A., \& Vliegenthart, J. F. G. (1992) Eur. J. Biochem. 207, 793-802.

Verhagen, J., Veldink, G. A., Egmond, M. R., Vliegenthart, J. F. G., Boldingh, J., \& Van der Star, J. (1978a) Biochim. Biophys. Acta 529, 369-379.

Verhagen, J., Vliegenthart, J. F. G., \& Boldingh, J. (1978b) Chem. Phys. Lipids 22, 255-259.

Vick, B. A., \& Zimmerman, D. C. (1987) in The Biochemistry of Plants (Stumpf, K. K., \& Conn, E. E., Eds.) Vol. 9, pp 53-89, Academic Press, New York.

Wang, Z.-X., Killilea, S. D., \& Srivastava, D. K. (1993) Biochemistry 32, 1500-1509. 